\title{
中文电视剧对印尼峇淡世界大学华文教育系学生汉语发展的作用调查研究 Analisis Peranan Film Mandarin dalam Perkembangan Bahasa Mandarin Mahasiswa Program Studi Pendidikan Bahasa Mandarin Universitas Universal Batam Indonesia
}

\author{
Sugato Wiry; Muk Fa \\ Universitas Universal-Batam
}

Email: sugatowiry.uvers@gmail.com; zhou_yu_quan@yahoo.co.id

\section{摘要}

中文电视剧对世界大学华文教育系学生的汉语发展引起发挥作用, 具有复杂多样的 原因所影响, 包括：观众开始观看中文电视剧的时间、观看中文电视剧的原因与动机、 观看中文电视剧的频率、观看过的中文电视剧的数量、观看的中文电视剧类型、观看中 文电视剧使用的字幕等。因此，本文采用了问卷调查法、访谈调查法、统计分析法、以 及描述解释法将中文电视剧对印尼峇淡世界大学华文教育系学生汉语发展的作用进行调 查分析。

通过对 50 位世界大学华文教育系学生的调查研究发现, 观看中文电视剧能以提高观 众的汉语四大基本技能：听、说、读、写能力。中文电视剧对 $84 \%$ 学生的听力能力提高 发挥作用; 对 $72 \%$ 学生的说话能力提高发挥作用; 对 $58 \%$ 学生的阅读能力提高发挥作用; 对 58\%学生的写作能力提高发挥作用。此外, 观看中文电视剧还能以增加观众有关中华 文化与历史的知识。

关键词: 峇淡; 世界大学华文教育系; 中文电视剧

\begin{abstract}
Abstrak
Film Mandarin berperan dalam perkembangan bahasa Mandarin mahasiswa Program Studi Pendidikan Bahasa Mandarin Universitas Universal Batam Indonesia, yang dipengaruhi oleh berbagai faktor yang beragam, seperti: waktu yang digunakan penonton untuk menonton film bahasa Mandarin, alasan dan motivasi untuk menonton film bahasa Mandarin, tingkat frekuensi menonton film bahasa Mandarin, berapa kali menonton film bahasa Mandarin, jenis film bahasa Mandarin, penggunaan subtitle film bahasa Mandarin, dan sebagainya. Dengan demikian, penelitian menggunakan metode kuisioner, wawancara, analisis statatik, dan metode deskriptif
\end{abstract}


untuk menganalisis Peranan Film Mandarin dalam Perkembangan Bahasa Mandarin Mahasiswa Program Studi Pendidikan Bahasa Mandarin Universitas Universal Batam Indonesia.

Melalui survei terhadap 50 mahasiswa Program Studi Pendidikan Bahasa Mandarin Universitas Universal, menonton film Mandarin dapat meningkatkan empat keterampilan dasar bahasa Mandarin: mendengar, berbicara, membaca, menulis. Film bahasa Mandarin berperan dalam meningkatkan kemampuan mendengar mahasiswa sebesar 84\%; meningkatkan kemampuan berbicara mahasiswa sebesar 72\%; meningkatkan kemampuan membaca mahasiswa sebesar 58\%; dan meningkatkan kemampuan menulis mahasiswa sebesar 58\%. Selain itu, menonton film bahasa Mandarin juga dapat menambah pengetahuan penonton tentang budaya dan sejarah Tiongkok.

Kata kunci: Batam; Program Studi Pendidikan Bahasa Mandarin Universitas Universal; Film Mandarin

\section{一 引言}

\section{1 研究背景}

自从 20 世纪电视在印尼发展以来已经引起了印尼人民观看电视剧的习惯。电视剧不 但提供了娱乐服务，观看电视剧的同时观众也可以获得知识，因此成为了一项日常的家 庭活动, 久而久之构成了社会大众生活方式的重要部分。

进入 21 世纪, 随着科技的发达, 电视剧也渗透网络, 人们可以通过电脑和手机观看 电视剧。如今随处可见，许多人在空闲时间都会拿出手机来观看电视剧，甚至有不少的 人会边工作边观看电视剧，尤其是年轻人。

电视剧是一种传播语言的媒体。剧中所说出的语言, 所使用的词语与语法, 所出现 的字体与字幕, 都会被观众吸收。电视剧是促进语言传播的工具, 因为观众在欣赏电视 剧的过程中, 不知不觉也习得电视剧中的语言。但不同背景、兴趣、年龄的观众, 对电 视剧中使用的语言有着各自的见解与收获。印尼峇淡世界大学华文教育系学生也是如此。 笔者对其现象感兴趣, 认为通过观看中文电视剧能以提供世界大学华文教育系学生的课 外自习法。希望通过本研究世界大学华文教育系学生能意识到中文电视剧对汉语学习的 
帮助。因此想更深了解并探索中文电视剧对印尼峇淡世界大学华文教育系学生汉语发展 的作用、后针对常出现的问题提出相关解决方案。

\section{2 研究目的和意义}

本研究的目的是为了了解中文电视剧对世界大学华文教育系学生的汉语发展的作用、 了解世界大学华文教育系学生观看中文电视剧的过程中遇见了什么样的困难并提出针对 性的解决方法。

笔者希望这项研究的结果可以提醒世界大学华文教育系学生观看中文电视剧对汉语 发展的好处, 并且优化中文电视剧对印尼峇淡世界大学华文教育系学生汉语发展的作用。

\section{3 研究方法}

\subsection{1 研究对象}

本文的研究对象来自世界大学华文教育系各种班级的 50 位学生。所有研究对象都有 着观看中文电视剧的习惯, 都是自愿填写本研究的调查问卷的。

\section{3 .2 问卷调查法}

\begin{tabular}{|c|c|}
\hline 学期 & 人数 \\
\hline 2 & 5 \\
\hline 4 & 9 \\
\hline 6 & 215 \\
\hline 8 & 总数 50 \\
\hline
\end{tabular}

笔者通过网络社交媒体分发调查问卷, 收集 50 位世界大学华文教育系学生有关观看 中文电视剧习惯的信息，包括：观看中文电视剧的频率、观看什么类型的中文电视剧、 过程中遇见了什么样的困难等方面。

\subsection{3 访谈调查法}

为得到更详细与更可靠的信息，笔者采取具有真实接触性的访问与面谈调查法，访 谈 20 位世界大学华文教育系学生有关观看中文电视剧的作用, 包括中文电视剧提高了观 众的汉语听说读写能力的哪些方面、通过剧中的哪些因素而提高观众的汉语听说读写能 力等。 


\section{3.4 统计分析法}

为了保证数据统计的正确性与可信性, 笔者使用微软 Excel 软件, 将已收集到的调查 资料进行统计。后把调查数据结果进行归纳分析。

\section{3.5 描述解释法}

笔者将统计分析后得出的调查数据结果, 对世界大学华文教育系学生观看中文电视 剧的状况进行描述。对常出现的问题进行分析解决问题，后提出相关解决方案。

\section{二 研究结果及探讨}

\section{1 观看中文电视剧提高听说读写技能的作用}

\subsection{1 观看中文电视剧提高听力能力}

中文电视剧中充满演员之间的对话，几乎每时每刻都是由对话而成。观众观看中文 电视剧必定听取剧中的对话, 过程中自然获得足够的语言输入, 有利于提高观众的汉语 听力能力。

通过对观众的访谈可了解听取剧中的对话不但能让观众了解汉语普通话的正确发音, 也能让观众对剧中种种的表达法耳熟。再加上以下几项因素, 帮助观众将所吸收的汉语 语言输入, 成为可理解性的语言输入:

\section{(1) 剧情}

中文电视剧的剧情让观众了解演员对话中大概是什么意思。虽说观众不了解剧中对 话的含义, 但观众还可以猜测其意义。久而久之当听到同样的词语观众便了解包含的意 义是什么。

\section{（2）表情与情感}

演员在对话中的表情与情感强调了剧中对话所包含的含义。观众便了解哪些词句可 以用来表达什么表情。通过中文电视剧中的对话加上剧情和演员的表情与情感, 观众不 但提高了自己的听力水平，同时也提高了对汉语普通话的理解力。

\section{(3) 对话速度}

剧中对话的速度能熟练观众的听力能力。对话中的快慢搭配让观众熟练抓住词句的 每一个词语，并熟练消化词句的含义的速度。 
除了剧中演员之间的对话, 剧中的电影配乐和歌曲也能为观众提供语言输入。总而 言之通过观看中文电视剧, 观众能以吸收足够具有可理解性的汉语语言输入。根据本文 对 50 位学生的调查研究发现中文电视剧对世界大学华文教育系学生的汉语发展最大的作 用在于提高学生的听力能力。中文电视剧提高了 42 位学生的听力能力, 也就是对 $84 \%$ 世界大学华文教育系观众的听力能力提高发挥作用。

\subsection{2 观看中文电视剧提高说话能力}

中文电视剧中提供大量的词汇量与表达方式，包括成语、歇后语、浐语、口号等。 近朱者赤, 近墨者黑。通过对观众的访谈可了解观看中文电视剧让世界大学华文教育系 学生能以吸收、模仿、发挥、后在交流过程中实践剧中的语言, 包括以下几项方面:

\section{(1) 语音}

世界大学华文教育系学生观看中文电视剧首次吸收的语言因素即是其语音。甚至汉 语零起点的初学者, 在观看中文电视剧的过程中也能吸收剧中语言的语音。因此观众对 标准的汉语语音也将渐渐熟悉, 包括声母韵母和声调的发音法。所以观众自然具有正确 的汉语语音的概念。

(2) 词汇

词汇是每一段话不可缺的重要部分。每一段话都由词汇所组成。因此世界大学华文 教育系学生在观看中文电视剧的过程中必定对剧中所使用的的词汇越来越耳熟。随着词 汇的越常出现, 观众对其词汇也越来越了解、越来越掌握。越长时间观看中文电视剧, 观众脑里所具备的词汇量也越来越多。

(3) 语法

中文电视剧中所说的每一段话, 肯定含有语法, 而且使用的语法是正确的语法, 包 括口语语法和书面语语法。世界大学华文教育系学生观看中文电视剧时非吸收剧中的语 法不可。因此观众自然对汉语语法感到不陌生。久而久之观众便了解、习惯并掌握使用 标准的、正确的汉语语法。

一旦能将上述实践在交流过程中, 随着时间的流逝, 世界大学华文教育系学生的说 话能力也将步步高升。根据本文对 50 位学生的调查研究发现中文电视剧提高了 36 位学 生的说话能力, 也就是对 $72 \%$ 世界大学华文教育系观众的说话能力提高发挥作用。 


\subsection{3 观看中文电视剧提高阅读能力}

中文电视剧一般使用汉语字幕来显示剧中对话的语言文字, 为帮助观众了解剧中对 话的含义。如之前所提到, 中文电视剧中充满演员之间的对话, 几乎每时每刻都是由对 话而成。剧中的字幕也随着演员的对话而浮现。因此世界大学华文教育系学生在观看中 文电视剧的过程中自然也阅读了剧中所浮现的的汉语字幕。通过对观众的访谈可了解阅 读剧中的汉语字幕能帮助观众提高阅读能力的这几项方面:

\section{(1) 阅读理解}

中文电视剧中的汉语字幕的作用是帮助观众了解剧中的对话。字幕所展现的文字让 观众了解剧中所说的话指的是什么意思。如之前所提到, 剧中的剧情和演员的表情与情 感也帮助观众了解剧中的对话。因此观众阅读剧中的字幕易于理解其含义。

\section{(2) 阅读速度}

阅读剧中的汉语字幕最突出的特点在于阅读速度。剧中的字幕随着对话的速度而浮 现。而剧中的对话速度变化无常, 对话的快慢搭配随着剧情的需求。在演员之间相互对 话的期间, 观众逼不得已非得追上字幕变化的速度并了解其内涵不可。因此观众在短短 的时间内必须消化其对话所包含的含义。久而久之观众将习惯使用最快的速度阅读汉语 文字并理解其意义。

根据本文对 50 位学生的调查研究发现中文电视剧提高了 29 位学生的阅读能力, 也 就是对 $58 \%$ 世界大学华文教育系观众的阅读能力提高发挥作用。

\subsection{4 观看中文电视剧提高书写与写作能力}

写作能力是语言四大语本技能: 听、说、读、写中最为后的技能。世界大学华文教 育系学生观看中文电视剧提高了前三个技能后, 其写作能力自然也随之提高。

写作能力的提高与说话能力的提高是一致性的过程, 因为两者同样通过获得足够可 理解性的语言输入后, 在此基础上对其输入做个模仿并自我发挥后, 再输出语言。区别 只在于其语体。说话能力靠的是对口头语的流利性。口头语是在日常口头交谈时使用的 语言, 因此与听力能力具有密切关系, 越多听就越会说。而书写与写作能力靠的是对书 面语的掌握。书面语是在书写或阅读文章时使用的语言, 因此与阅读能力具有密切关系, 越多读, 就越会写。 
另外，书写与写作严格要求正确的认字、恰当的选用词、使用标准的语法与美丽的 修辞等。如之前所提到, 通过观看中文电视剧, 观众脑里所具备的词汇量也越来越多, 对汉语标准的、正确的语法也越来越了解、越来越掌握。根据本文对 50 位学生的调查研 究发现中文电视剧提高了 29 位学生的书写与写作能力, 也就是对 $58 \%$ 世界大学华文教 育系观众的书写与写作能力提高发挥作用。

\section{2 观看中文电视剧增加中华文化与历史知识}

\subsection{1 观看中文电视剧增加中华文化知识的作用}

每个国家都具有不同的文化习俗, 无论是在衣食住行、习惯爱好、喜丧嫁娶等礼仪 上都存在较大的差异。一直以来为了了解某个他国家的文化习俗, 就必须到该国家入乡 随俗。而如今中文电视剧已提供许多有关中华文化的知识, 尤其古代性的中文电视剧。

不同的电视剧、不同的剧情、不同的场面含有不同的中华文化。所以中文电视剧中 的中华文化复杂多样。所谓中华文化的知识指的是民族的文明、风俗习惯与精神的总和。 包括中国历史、传统节日、小贤文化、慈善文化、爱国精神、中医文化、饮食文化、服 装文化、音乐与乐器、建筑风格等。这些文化将会体现在剧中演员的所行所为、一举一 动，包括说话方式、穿着方式、思想观念等。

通过观看中文电视剧, 能让世界大学华文教育系学生身为华侨华人、身为汉语第二 语言学习者更好地了解中华文化, 增加有关中华文化知识, 提高学习者对目的语国家的 认识程度。除此以外, 也是对祖先的孝敬的一种表现。

\subsection{2 观看中文电视剧增加中国历史知识的作用}

自古以来前人为了保留各国的历史, 将该国的历史故事记载在历史书上。所以为了 了解某国国家的历史，就必须阅读有关该国家的历史书。而现在历史故事的记载，已经 使用电视剧为记载媒体。

如今可见，小部分中文电视剧以中国历史故事为题材。比如《三国演义》、《汉武 大帝》、《武则天》、《孔子》、《秦始皇》等。甚至有不少以中国历史故事为题材的 中文电视剧进行翻拍。目的是为了让更多的人能因观看其电视剧而了解中国历史, 并且 铭记于心。 
观看中国历史剧是了解中国文化最好方法之一。比起阅读中国悠久的历史故事, 观 看以中国历史故事为题材的中文电视剧远远更吸引学习者的注意力。因为观众可以同时 观看剧中的情景, 听到演员之间的对话。所以观众似乎进入在故事中, 因此观众更真实 与深入的了解到中国历史。通过了解中国历史观众能以得取历史中的教训。

\section{3 观看中文电视剧面临的问题并提出针对性的解决方案}

\subsection{1 观看中文电视剧面临的问题}

世界大学华文教育系学生在观看中文电视剧时或多或少肯定遇见一些问题, 因此从 中习得的过程便受阻碍。笔者将世界大学华文教育系学生观看中文电视剧是出现的问题 归纳为 4 大问题，包括：听不清楚；无法阅读字幕；不了解对话中的意思；没有印尼语 字幕无法了解意思。调查研究发现在 4 大问题中，最常出现的问题是听不清楚剧中的对 话, 30 位学生赞同。7 位学生赞同无法阅读字幕是常出现的问题之一。21 位学生赞同不 了解对话中的意思是常出现的问题之一。8 位学生赞同没有印尼语字幕无法了解意思是常 出现的问题之一。

\begin{tabular}{|c|c|c|}
\hline 问题 & 赞同 & 占百分比 \\
\hline 听不清楚 & 30 & $60 \%$ \\
\hline 无法阅读字幕 & 7 & $14 \%$ \\
\hline 不了解对话中的意思 & 21 & $42 \%$ \\
\hline 没有印尼语字幕无法了解意思 & 8 & $16 \%$ \\
\hline
\end{tabular}

\subsection{2 为提高听力能力, 反复听取为佳}

Rost（1994）指出: “听力在语言教学中起着至关重要的作用, 因为它为学习者提供 了语言输入, 如果不能正确理解输入, 学习就无从开始。” 所以为了保证中文电视剧对 提高听力能力的作用达到最佳效果, 就要确认观众正确理解所听取的语言输入。

每当遇见剧中难以理解的对话, 建议观众重复听取其部分。并非将难以理解的部分 做个猜测后再继续观看, 甚至忽略其部分。根据本研究所发现, 大多数的世界大学华文 教育系学生上线观看中文电视剧, 因此观看中文电视剧时能以反复观看、反复听取。 
除此以外, 当观众面临较难以理解的语句时, 建议观众将其对话记下来, 后上网查 收其意义。该方法能以提高听力能力。一旦理解了一部分对话, 之后若出现同样或相似 的句子, 观众便易于理解其意义。若真无法理解其意义，建议观众选择观看其他使用较 易于理解的中文电视剧。当观众的汉语水平已达到了一定的程度之后, 再升级观看使用 较高级语言的中文电视剧。

\subsection{3 为提高说话能力, 日常生活中使用为佳}

Bygate（1987）提出：“口语交际应该被理解为技能而不是知识。” 通过观看中文电 视剧所习得的生词、成语, 及其它各种表达法属于知识。但如果没实践在日常生活中, 便是一知半解。虽然观众观看中文电视剧后了解了某个成语的内涵, 但在日常生活真实 对话中未必能恰当并流利使用。只要观众将剧中所习得的语言反复实践在日常生活真实 对话中, 才能让观众对其了如指掌。

\section{3. 4 为提高阅读能力, 观看中文电视剧的同时阅读汉语字幕为佳}

Grabe 和 Stoller (2002) 认为, 流畅的阅读表现为一整套复杂的过程。比如, 阅读 应该是快速、有效、交互式的过程，读者需要在识别词语的同时，分析句子结构，并赋 予其正确的意义，另外还需激活相应的背景知识用以帮助理解语言材料。

中文电视剧中的字幕满足了上述流畅阅读的几项特点。剧中字幕的切换速度随着演 员之间对话的速度。因此观众阅读剧中字幕必须跟上对话的速度。字幕的主要功能是让 观众易于理解剧中的对话, 所以观众逼不得已必须理解其对话的意思。在这种情况下, 观众在观看中文电视剧时便自我要求必须仔细阅读字幕、在短短时间内分析句子的结构、 并理解其意义。

\section{3.5 为提高书写与写作能力, 反复手写汉字为佳}

如上述所提到, 观看中文电视剧让观众从中获得语言输入。通过长期听取剧中的对 话, 久而久之观众便熟背剧中的某些成语、口号、或其他较特殊的说法, 自然在写作过 程中能以使用。不仅如此, 通过阅读剧中的字幕, 观众便了解正确的选用字, 汉字结构 也印在脑里了。因此在手写写作时观众便能顺利写出常出现在剧中的汉字。但为了达到 其最佳效果, 观众必须反复手写汉字, 熟练手写汉字字体后, 自然无障碍写出每一个单 字。 


\section{三 结论}

中文电视剧是个四通八达的汉语学习媒体。通过观看中文电视剧, 世界大学华文教 育系学生不但能以提高汉语四大基本技能: 听、说、读、写, 还增加了观众对中华文化 与中国历史的知识。因此在满足娱乐需求的同时, 还可以习得剧中的语言技能与知识。

中文电视剧对世界大学华文教育系学生的汉语发展能否发挥作用具有复杂多样的原 因所影响, 包括: 观众开始观看中文电视剧的时间, 观看中文电视剧的原因与动机, 观 看中文电视剧的频率, 观看过的中文电视剧的数量, 观看的中文电视剧类型, 观看中文 电视剧使用的字幕等。

中文电视剧对世界大学华文教育系学生汉语发展最突出的作用在于提高汉语四大基 本技能: 听、说、读、写能力。根据本文对 50 世界大学华文教育系学生的调查研究指出: 中文电视剧对 $84 \%$ 世界大学华文教育系学生的听力能力提高发挥作用; 对 $72 \%$ 世界大学 华文教育系学生的说话能力提高发挥作用; 对 58\% 世界大学华文教育系学生的阅读能力 提高发挥作用; 对 $58 \%$ 世界大学华文教育系学生的书写与写作能力提高发挥作用。

为让中文电视剧对世界大学华文教育系学生的汉语发展发挥最佳作用, 使用汉语字 幕最为好。通过同时进行观看中文电视剧与阅读其汉语字幕的过程，除了让观众更易于 了解剧中对话的含义, 所吸收的语言输入成为可理解性的语言输入之外, 观众也随着时 间的流逝而而越来越认识、熟悉、了解、并掌握剧中的语言运用。因此观众在满足自己 的娱乐需求的同时, 可以提高汉语听、说、读、写的能力, 并增加观众对中华文化的知 识。

本研究的不足之处在于本文无有详细指出世界大学华文教育系学生观看中文电视剧 后的汉语发展达到什么样的程度，无有对比观众观看中文电视剧之前与之后的区别。加 之笔者缺乏理论知识, 因此在整篇论文的分析不够严谨, 还有许多疏漏与错误。敬请各 位教师给予批评与指正。 


\section{参考文献}

[1] 程晓堂. 第二语言教学研究中的前沿问题 [M]. 北京: 北京师范大学出版社, 2014.

[2] 方明建. 大学课堂多媒体教学的困境与突破 $[\mathrm{J}]$. 中国大学教学，2013，（2），65-66, 82.

[3] 李亮. 西北师范大学多媒体教学现状调查研究 [D]. 西北师范大学硕士学位论文, 2015.

[4] 刘珊珊. 中文电影在对外汉语视听说教学中的应用 [D]. 黑龙江大学硕士学位论文, 2014.

[5] Second Language Acquisition [EB/OL]. (2019-02-29)[2020-4-12]. https://wenku. baidu. com/view/ea19df5477232f60ddcca173. html.

\section{Catatan:}

Artikel pernah dipresentasikan pada Seminar Nasional APSMI 24 Oktober 2020 